\title{
Ambivalence over Expression of Anger and Sadness Mediates Gender Differences in Depressive Symptoms
}

\author{
Laura E. Kunst $^{1,2}$. Judith de Groot ${ }^{1} \cdot$ A. J. Willem van der Does ${ }^{1}$
}

Published online: 26 July 2018

(c) The Author(s) 2018

\begin{abstract}
The gender difference in the prevalence of depression is well-documented, poorly understood and multifactorial. Considering that gender differences exist in the expression of emotions, we hypothesized that ambivalence over the expression of sadness and anger contributes to the difference in depression scores between men and women. Questionnaires on depressive symptoms and ambivalence regarding sadness and anger expression were completed by 550 respondents (66.9\% women, average age 27.8 years). Women reported more depressive symptoms and were more ambivalent over the expression of both sadness and anger than men. Ambivalence over sadness and—to a lesser extent—anger mediated the relationship between gender and depressive symptoms. We conclude that ambivalence over emotion expression may partly explain why depression occurs more frequently in women than men.
\end{abstract}

Keywords Depression · Sex · Gender · Ambivalence over emotional expression · Emotional expressiveness $\cdot$ Sadness · Anger

\section{Introduction}

A highly consistent finding in research on depression is its higher prevalence among women than men (Salk et al. 2017). Explanations for this female preponderance have been proposed in terms of cognitive (e.g. rumination; NolenHoeksema 2012), biological (e.g. genetic vulnerability; e.g. Klok et al. 2011) and affective (e.g. emotional reactivity; Hyde et al. 2008) factors. Furthermore, some stressful life events occur more frequently in women than men (e.g. sexual abuse; Hyde et al. 2008).

It has recently been proposed that ambivalence over emotional expression (AEE) increases depression risk

Electronic supplementary material The online version of this article (https://doi.org/10.1007/s10608-018-9937-2) contains supplementary material, which is available to authorized users.

Laura E. Kunst

1.e.kunst@uvt.nl

1 Institute of Psychology, Leiden University, Wassenaarseweg 52, 2333 AK Leiden, The Netherlands

2 Present Address: Department of Medical and Clinical Psychology, Tilburg School for Social and Behavioral Sciences, Tilburg University, T417 Tias Building, Warandelaan 2, 5037 AB Tilburg, The Netherlands
(Brockmeyer et al. 2013). AEE denotes the conflict that arises when one wants to express emotions, but feels reluctant to do so (King and Emmons 1990). AEE may develop as a result of negative experiences when displaying emotions (Brockmeyer et al. 2013). Psychological abuse and parental punishment in early life, for instance, have been linked with emotional inhibition (Krause et al. 2003). In the short-term, AEE may benefit the individual, as it may reduce anxiety or protect one from social rejection (King and Emmons 1990). As a form of avoidance, AEE may contribute to psychological distress in the long term, leading to depressive and anxiety symptoms (Krause et al. 2003). Some overlap exists between AEE and other emotional constructs (e.g., alexithymia), both conceptually and in their measurement (Quinton and Wagner 2005). AEE differs from alexithymia in that it pertains to the disclosure of emotions rather than the identification or internal regulation of emotions (Müller et al. 2008).

Although research shows that AEE is related to depression status and severity (Brockmeyer et al. 2013), longitudinal studies are needed to clarify the nature of this relationship. Wanting but not being able to express one's emotions may give rise to intrapersonal conflict and distress that directly affect one's well-being (Brockmeyer et al. 2013). Avoiding emotional expression in daily life may 
also interfere with social functioning (Mongrain and Zuroff 1994). For instance, people may not receive the support they need if others are unaware of their distress or sadness. Displaying sadness may elicit social support (Hendriks et al. 2008), which buffers against the effects of stress (Gariépy et al. 2016; Rueger et al. 2016). Other studies suggest that hiding feelings of anger contributes to more submissive, less congruent, and ineffective communication styles (Mongrain and Vettese 2003). In line with these proposed mechanisms, AEE mediated the effects of stressful life events on negative affect (Ben-Zur and Zimmerman 2005), but reverse causation cannot be ruled out on the basis of this study.

It is possible that AEE contributes to depression and partially explains the higher prevalence of depression in women than in men. Women tend to have higher AEE scores than men (King and Emmons 1990). As AEE is also linked to depression (Brockmeyer et al. 2013), we investigated a mediational model in which gender differences in AEE contribute to the gender differences in depression. No previous studies have investigated gender differences in AEE in relation to depression.

Furthermore, prior studies did not distinguish between different negative emotions. King and Emmons (1990) found that women had slightly higher AEE scores than men and were more expressive of emotions. These differences were restricted to positive emotions; no gender differences were observed in AEE and emotional expressiveness for negative emotions (King and Emmons 1990). However, different negative emotions, such as anger and sadness, were not assessed separately in that study.

Distinguishing between negative emotions seems relevant in research on gender differences, as social consequences of negative emotional expression appear to vary by gender and by emotion. Women tend to express more 'vulnerable' emotions, including anxiety and sadness, whereas men show more 'powerful' emotions, such as anger (Santagio-Menendez and Campbell 2013; Martin et al. 2013). Furthermore, boys, but not girls, are accepted less by their peers when they express sadness (Perry-Parisch and Zeman 2011). Anger expression has also been shown to decrease women's, but not men's, likability (Williams and Tiedens 2016).

In summary, AEE seems to differ as a function of gender and type of emotion. Women may experience more ambivalence to express anger, which may contribute to their higher risk of depressive symptoms compared with men. Men may experience more ambivalence to express sadness and consequently report fewer depressive symptoms than women. Considering the adaptive functions of displaying sadness (Hendriks et al. 2008), high AEE sadness scores might also be associated with less social support and more depressive symptoms. In that case, women would be expected to also have higher AEE sadness scores than men.
The aim of the present study was to (1) examine gender differences in AEE for sadness and anger; and (2) explore the role of AEE as a possible mediator or moderator in the relationship between gender and depression. We hypothesized that women would have higher AEE anger scores (Santagio-Menendez and Campbell 2013) and lower AEE sadness scores (Martin et al. 2013) than men, and that these differences would contribute to higher depressive symptoms in women vs. men. We also hypothesized that AEE sadness and anger would be more strongly related to depressive symptoms in women than in men. Finally, we explored whether the relation between gender and AEE varies between individuals with lower vs. higher levels of depressive symptoms.

\section{Methods}

\section{Procedure}

A web-based survey on AEE and depressive symptoms was distributed by means of social media. Responses were collected between March 22nd 2016 and April 11th 2016. Gift cards valued $50(1 \times), 30(1 \times), 20(1 \times)$ and 10 euros $(10 \times)$ were randomly distributed amongst participants who completed the questionnaire ( $2.4 \%$ chance to win). The study was approved by the Psychology Research Ethics Committee (PREC \#9140377315).

\section{Respondents}

Respondents were 550 individuals, $66.9 \%$ female, average age 27.8 years $(\mathrm{SD}=12.0)$. The sample was highly educated: $10.7 \%$ primary or secondary education only; $10.5 \%$ vocational training; $32.9 \%$ applied sciences degree or student; $45.8 \%$ university college degree or student. Almost all (95.1\%) were Dutch.

\section{Questionnaires}

Depressive symptoms were assessed using the Quick Inventory of Depressive Symptomatology-Self Report (QIDS-SR; Rush et al. 2003). The QIDS-SR has high internal consistency (Cronbach's $\alpha=0.86$ ) and correlates highly with the original IDS $(r=.96)$. Respondents indicate to what extent they have experienced each of the 16 depressive symptom items in the past 7 days (e.g., 'Feeling sad', with scores ranging from $0=$ 'I did not feel sad' to $3=$ 'I felt sad nearly all of the time'). Internal consistency in this study was acceptable (Cronbach's $\alpha=0.75$ ). A QIDS-SR score of $6-10$ is the 'mild severity' range, comparable to BDI scores 10-18 
(Rush et al. 2003/http://www.ids-qids.org/interpretation. html)

AEE sadness and anger were measured using a modified version of the 28-item Ambivalence over Emotional Expressiveness Questionnaire (AEQ; King and Emmons 1990). The AEQ has a high internal consistency (Cronbach's $\alpha=0.89$; King and Emmons 1990). To assess AEE sadness and anger specifically, seven questions were selected and adapted to measure sadness or anger. Most AEQ items are phrased in a way that would require major adaptations if applied to other emotions (e.g., item 14, 'I try to show people I love them, although at times I am afraid that it may make me appear weak or too sensitive', cannot be converted to anger and sadness without major revisions). Items 1, 3, 4, 6, 8, 23 and 25 were therefore selected and adapted to measure sadness and anger instead of 'emotions' (e.g. item 1 'I want to express my sadness/anger honestly, but I am afraid that this will bring shame or hurt'; Appendix A). Each item was scored on a 4-point Likert scale ranging from 1 (never) to 4 (always).

A confirmatory factor analysis (SPSS version 22, AMOS) confirmed the structure of two interrelated latent factors, each estimated using 7 items with unique variances. When accounting for dependence of variances among four pairs of item variances (see Appendix B), the model fit indices were satisfactory: $\mathrm{RMR}=0.027$ (should be below .05), $\mathrm{CFI}=0.958$ (should be larger than 0.95), $\mathrm{RMSEA}=0.065$ (should be between .05 and .07; see Appendix B for the full model). Furthermore, internal consistencies of both AEE sadness (Cronbach's $\alpha=0.91$ ) and AEE anger (Cronbach's $\alpha=0.87$ ) were good.

Respondents were additionally asked to indicate how frequently they want to express sadness and anger ("When you feel sad/angry, how often do you feel the need to express this?"). These 1-item questions were added in the present study to explore whether low AEE scores would merely reflect a low need to express these emotions. These items were scored on one 7-point Likert scale ranging from 1 (never) to 7 (always).

\section{Statistical Analysis}

We used SPSS version 22, with alpha set at .05 for all statistical tests. We carried out (i) mediation analyses according to the Baron and Kenny (1986) method and the indirect effects method (Preacher and Hayes 2008); (ii) moderation analyses on the relation between AEE sadness/anger and depressive symptoms by gender; and iii) moderation analyses on the relation between gender and AEE sadness/ anger by depression status. In all analyses we controlled for age, education level and need to express sadness/anger. Because some variables (e.g., age, depression scores) and their residuals were not normally distributed, all analyses were bootstrapped (5000 repetitions, bias corrected accelerated (BCA) confidence intervals (CI), stratified by gender, in line with recommendations of Barber and Thompson 2000; Neal and Simon 2007; and Parra-Frutos 2014).

Firstly, following the Baron and Kenny (1986) method, two mediation models were tested using linear regression analyses. The first step tested gender differences in depression. The second step tested whether the independent variable (gender) and the mediators AEE sadness and anger were related. The third and fourth steps tested whether AEE sadness and anger were related to depression, controlled for gender.

The indirect effects analysis was performed using the INDIRECT SPSS macro (Preacher and Hayes 2008), with gender as the independent variable, QIDS depression scores as dependent variable, AEE sadness and anger entered simultaneously as mediators, 5000 bootstrap samples and BCA CIs. This method compares the direct effects of the independent variable (gender) on the dependent variable (depression) with the indirect effects of the independent variable on the dependent variable through the mediator(s).

The Baron and Kenny approach requires between 530 and 562 respondents for a statistical power of 0.8 , assuming small path sizes and a direct effect larger than zero (see Table 3 in Fritz and MacKinnon 2007). The required number of respondents decreases as the path sizes between independent, mediating and dependent variables increase (e.g., $74-118$ cases are required when these paths are medium in size, assuming the direct effect is larger than zero). Bias corrected bootstrap methods require at least 462 cases assuming small path sizes, and 71 cases assuming medium path sizes, for a power of 0.8. Our sample size therefore provides sufficient statistical power for both statistical approaches.

Secondly, two moderation analyses were conducted using the PROCESS SPSS macro (Preacher and Hayes 2008). The first moderation analysis included AEE sadness as independent variable, depressive symptoms as dependent variable, and gender as moderator. A significant interaction term (AEE sadness * gender) would indicate that the effects of AEE sadness on depressive symptoms vary by gender. This analysis was repeated using AEE anger as the independent variable. Both analyses were bootstrapped using 5000 samples and BCA CIs.

Thirdly, two moderation analyses on the relation between gender and AEE sadness/anger by depression status were conducted. Two groups were created using the QIDS-SR classification of no depression (QIDS-SR $<6$; $\mathrm{N}=319$ ) and at least mild depressive symptoms (QIDS$\mathrm{SR}>6 ; \mathrm{N}=231)$. These moderation analyses were also conducted using PROCESS (Preacher and Hayes 2008), with gender as independent variable, AEE sadness (first analysis) or AEE anger (second analysis) as dependent variable, and depression status as moderating variable. 
A significant interaction term (e.g., gender * depression status) would indicate that the gender differences in AEE sadness are more pronounced in the depressed or nondepressed subgroup.

\section{Results}

A total of 706 respondents started the questionnaire and 550 completed it (77.9\%). Completers had no missing values. Fifty-seven women (15.5\%) and 15 men (8.3\%) were at least moderately depressed (QIDS-SR $>10$ ). The total mean QIDS-SR depression score was 5.6 $(\mathrm{SD}=4.1)$, which is around the cut-off score (6) of non-depressed vs. mildly depressed (Schulte-van Maaren et al. 2013; Rush et al. 2003; Wahl et al. 2014).

\section{Mediation Models}

Women had significantly higher QIDS-SR depressive symptom scores than men (Table 1). Gender predicted AEE sadness scores, $B=-1.31, S E=0.43, t(549)=-2.96$, $p=.002, \mathrm{CI}-2.11$ to $-0.51, R^{2}=.05, F(7,542)=4.01$, $p<.001$. However, contrary to our hypotheses, women $(M=13.6, \mathrm{SD}=4.8)$ scored higher on AEE sadness than men $(M=12.1, \mathrm{SD}=4.4)$. Women also scored higher than men on the need to express sadness $(M=3.9, \mathrm{SD}=1.2 \mathrm{vs}$. $M=3.2, \mathrm{SD}=1.1)$. Need to express and ambivalence scores were not significantly related, $r(548)=.03, p=.423$.

Furthermore, although women $(M=13.1, \mathrm{SD}=4.3)$ reported more AEE anger than men $(M=12.2, \mathrm{SD}=4.0)$ univariately $(B=-0.91, S E=0.37, t(549)=-2.37$, $p=.018$ ), these differences disappeared when controlling for age, need to express sadness and anger, and education
Table 1 Mediation models of depressive symptoms

\begin{tabular}{|c|c|c|c|c|c|c|c|}
\hline & \multirow[t]{2}{*}{$B$} & \multirow[t]{2}{*}{$S E$} & \multirow[t]{2}{*}{$t$} & \multirow[t]{2}{*}{$p$} & \multicolumn{2}{|c|}{$95 \%$ BCA CI } & \multirow[t]{2}{*}{$R^{2}$} \\
\hline & & & & & Lower & Upper & \\
\hline \multicolumn{8}{|c|}{ Step 1 in both Baron and Kenny models } \\
\hline Male gender & -0.92 & 0.37 & -2.43 & .007 & -1.66 & -0.22 & \multirow[t]{8}{*}{$.059 *$} \\
\hline Age & -0.06 & 0.01 & -4.08 & .001 & -0.09 & -0.04 & \\
\hline Need to express sadness & -0.09 & 0.16 & -0.56 & .593 & -0.39 & 0.21 & \\
\hline Need to express anger & 0.17 & 0.16 & 1.24 & .262 & -0.11 & 0.49 & \\
\hline \multicolumn{7}{|l|}{ Education $^{\mathrm{a}}$} & \\
\hline Vocational training & 0.69 & 0.79 & 0.93 & .381 & -0.75 & 2.03 & \\
\hline Applied sciences & 0.23 & 0.66 & 0.38 & .740 & -1.11 & 1.42 & \\
\hline University college & -0.82 & 0.63 & -1.4 & .200 & -2.12 & 0.42 & \\
\hline \multicolumn{8}{|c|}{ Step 3-4 in Baron and Kenny model for AEE sadness } \\
\hline Male gender & -0.35 & 0.32 & -1.07 & .282 & -0.97 & 0.25 & \multirow[t]{9}{*}{$.300 * *$} \\
\hline AEE Sadness & 0.43 & 0.04 & 13.64 & .001 & 0.37 & 0.51 & \\
\hline Age & -0.04 & 0.01 & -2.81 & .004 & -0.06 & -0.01 & \\
\hline Need to express sadness & -0.05 & 0.13 & -0.35 & .728 & -0.28 & 0.20 & \\
\hline Need to express anger & 0.08 & 0.13 & 0.64 & .539 & -0.14 & 0.31 & \\
\hline \multicolumn{7}{|l|}{ Education $^{\mathrm{a}}$} & \\
\hline Vocational training & 0.72 & 0.75 & 1.12 & .337 & -0.63 & 2.14 & \\
\hline Applied sciences & 0.65 & 0.56 & 1.24 & .245 & -0.41 & 1.82 & \\
\hline University college & -0.52 & 0.53 & -1.03 & .339 & -1.50 & 0.53 & \\
\hline \multicolumn{8}{|c|}{ Step 3-4 in Baron and Kenny model for AEE anger } \\
\hline Male gender & -0.80 & 0.34 & -2.23 & .021 & -1.47 & -0.12 & \multirow[t]{9}{*}{$.153 * * *$} \\
\hline AEE Anger & 0.31 & 0.04 & 7.71 & .001 & 0.22 & 0.40 & \\
\hline Age & -0.06 & 0.01 & -4.10 & .001 & -0.09 & -0.03 & \\
\hline Need to express sadness & -0.24 & 0.15 & -1.68 & .102 & -0.54 & 0.06 & \\
\hline Need to express anger & -0.03 & 0.13 & -0.21 & .832 & -0.27 & 0.24 & \\
\hline \multicolumn{7}{|l|}{ Education $^{\mathrm{a}}$} & \\
\hline Vocational training & 0.73 & 0.78 & 1.03 & .340 & -0.89 & 2.49 & \\
\hline Applied sciences & 0.42 & 0.60 & 0.73 & .494 & -0.77 & 1.75 & \\
\hline University college & -0.72 & 0.56 & -1.31 & .204 & -1.93 & 0.52 & \\
\hline
\end{tabular}

$* F(7,542)=4.89, p<.001, * * F(8,541)=29.004, p<.001, * * * F(8,541)=12.18, p<.001$

${ }^{a}$ Reference category: primary or secondary education only 
level. The need to express sadness $(B=0.52, S E=0.17$, $t(549)=3.34, p=.002$, CI 0.23 to 0.82$)$ and anger $(B=0.66$, $S E=0.18, t(549)=4.57, p=.002$, CI 0.30 to 0.99$)$ predicted AEE anger and appeared to eliminate the gender differences in AEE anger. Consequently, in the second step of the Baron and Kenny (1986) procedure for AEE anger, gender was not related to AEE anger $(B=-0.37, S E=0.38$, $t(549)=-0.964, p=.333, R^{2}=.09, F(7,542)=7.16$, $p<.001)$. AEE anger and AEE sadness correlated moderately high, $r(548)=.46, p<.001$. Gender correlated with the need to express sadness, $r(548)=-.26, p<.001$, but not anger, $r(548)=.08, p=.07$. The correlation between need to express anger and AEE anger was low, $r(548)=.24$, $p<.001$. When controlling for AEE sadness $(B=0.41$, $t(549), p<.001)$, gender no longer predicted AEE anger $(B=-0.29, t(549), p=.406)$.

The third and fourth step tested whether gender differences in depression were maintained, when controlling for AEE sadness and anger. Our hypothesized model concerning sadness (men are more ambivalent regarding sadness) was disconfirmed in step two. We therefore tested whether the higher depressive scores among women were mediated by women's higher AEE sadness scores. The relationship between gender and depressive symptoms was fully mediated by AEE sadness (Table 2): when controlled for AEE sadness, gender differences in depressive symptoms were no longer significant.

Furthermore, we expected that women's higher depression scores were mediated by their higher AEE anger scores compared with men. As step two did not show a straightforward relationship between gender, AEE anger and the need to express anger and sadness, we carried out the third and fourth steps of the Baron and Kenny (1986) procedure to explore these relationships. Table 2 shows that AEE anger predicts depressive symptoms, also when corrected for gender. In this model gender remains a significant predictor, suggesting partial mediation (Table 2). Combined with results from step two, results presented in Table 2 indicate

Table 2 Effects of AEE on depression, moderated by gender

\begin{tabular}{|c|c|c|c|c|c|c|c|}
\hline & \multirow[t]{2}{*}{$B$} & \multirow[t]{2}{*}{$S E$} & \multirow[t]{2}{*}{$t$} & \multirow[t]{2}{*}{$p$} & \multicolumn{2}{|c|}{$95 \%$ BCA CI } & \multirow[t]{2}{*}{$R^{2}$} \\
\hline & & & & & Lower & Upper & \\
\hline \multicolumn{8}{|l|}{ AEE sadness } \\
\hline Male gender & 1.25 & 0.93 & 1.35 & .179 & -0.57 & 3.08 & .30 \\
\hline AEE Sadness & 0.60 & 0.09 & 6.32 & $<.001$ & 0.41 & 0.78 & $F(9,540)=26.27, p<.001$ \\
\hline Male gender * AEE Sadness & -0.13 & 0.07 & -1.84 & .066 & -0.263 & 0.01 & \\
\hline Age & -0.04 & 0.01 & -2.87 & .004 & -0.06 & -0.01 & $\Delta R^{2}$ due to interaction term \\
\hline Need to express sadness & -0.04 & 0.13 & -0.28 & .777 & -0.29 & 0.22 & .004 \\
\hline Need to express anger & 0.08 & 0.12 & 0.62 & .535 & -0.16 & 0.31 & $F(1,540)=3.40, p=.066$ \\
\hline \multicolumn{8}{|l|}{ Education $^{\mathrm{a}}$} \\
\hline Vocational training & 0.71 & 0.64 & 1.10 & .27 & -0.56 & 1.97 & \\
\hline Applied sciences & 0.67 & 0.52 & 1.27 & .20 & -0.36 & 1.69 & \\
\hline University college & -0.53 & 0.50 & -1.06 & .29 & -1.51 & 0.45 & \\
\hline \multicolumn{8}{|c|}{ Conditional effects of AEE sadness on depression by gender } \\
\hline Women & 0.47 & 0.04 & 12.54 & $<.001$ & 0.40 & 0.54 & \\
\hline Men & 0.34 & 0.06 & 5.89 & $<.001$ & 0.23 & 0.46 & \\
\hline \multicolumn{8}{|l|}{ AEE anger } \\
\hline Male gender & -0.35 & 1.12 & -0.32 & .752 & -2.54 & 1.84 & .15 \\
\hline AEE anger & 0.35 & 0.12 & 3.04 & .003 & 0.13 & 0.58 & $F(9,540)=10.83, p<.001$ \\
\hline Male gender * AEE Anger & -0.04 & 0.08 & -0.43 & 670 & -0.20 & 0.13 & \\
\hline Age & -0.06 & 0.01 & -4.11 & $<.001$ & -0.09 & -0.03 & $\Delta R^{2}$ due to interaction term \\
\hline Need to express sadness & -0.25 & 0.15 & -1.70 & .090 & -0.53 & 0.04 & .0003 \\
\hline Need to express anger & -0.03 & 0.14 & -0.18 & .854 & -0.29 & 0.24 & $F(1,540)=0.18, p=.670$ \\
\hline \multicolumn{8}{|l|}{ Education $^{\mathrm{a}}$} \\
\hline Vocational training & 0.72 & 0.71 & 1.01 & .311 & -0.67 & 2.11 & \\
\hline Applied sciences & 0.42 & 0.58 & 0.72 & .472 & -0.72 & 1.55 & \\
\hline University college & -0.73 & 0.55 & -1.33 & .185 & -1.82 & 0.35 & \\
\hline \multicolumn{8}{|c|}{ Conditional effects of AEE anger on depression by gender } \\
\hline Women & 0.32 & 0.05 & 6.77 & $<.001$ & 0.23 & 0.41 & \\
\hline Men & 0.28 & 0.07 & 3.92 & $<0.001$ & 0.14 & 0.42 & \\
\hline
\end{tabular}

${ }^{\mathrm{a}}$ Reference category: primary or secondary education only 
that AEE anger partially mediates the relation between gender and depressive symptoms, but not when controlled for the need to express sadness and anger.

The analyses were repeated using indirect effects (Preacher and Hayes 2008), with gender as independent variable, depression scores as dependent variable, and AEE sadness and anger as mediators. Gender was related to AEE sadness, but not AEE anger, when controlling for age, education and the need to express sadness and anger (AEE sadness, $B=-1.31, S E=0.44, t(549)=-2.96, p<.003$; AEE anger, $B=-0.37, S E=0.39, t(549)=-0.96, p=.336)$ and both mediators were related to depression scores (AEE sadness, $B=0.39, S E=0.04, t(549)=11.02, p<.001$; AEE anger, $B=0.10, S E=0.04, t(549)=2.49, p=.013)$. The total effect of gender on depression $(B=-0.92, S E=0.38$, $t(549)=-2.43, p=.016)$ consisted of a significant total indirect effect of gender on depression through the mediators AEE sadness and anger (BCA CI -0.95 to -0.17 ); the remaining direct effect of gender on depression was not significant $(B=-0.37, t(549)=-1.12, p=.263)$.

Inspection of the mediators revealed that AEE sadness (BCA CI -0.90 to -0.18 ), but not AEE anger (BCA CI -0.17 to 0.03 ), were significant mediators in the final model $\left(R^{2}=.31, F(9,540)=26.72, p<.001\right)$. In a repetition of these analyses without controlling for the need to express sadness and anger, AEE anger was a significant partial mediator in the final model (BCA CI -0.22 to $-0.01 ; R^{2}=.28$, $F(3,546)=72.11, p<.001)$.

\section{Moderation by Gender}

Furthermore, two moderation analyses were carried out to assess whether the relation between AEE sadness/anger and depressive symptoms would differ by gender. Table 2 shows that the relation between AEE sadness and anger was not significantly different for men and women.

\section{Moderation by Depression Status}

Finally, we explored whether the relation between gender and AEE sadness/anger would differ as a function of depression status. Table 3 shows that the relation between gender and AEE sadness and anger was not significantly different for individuals with or without depressive symptoms.

\section{Discussion}

The aim of the current study was to investigate whether ambivalence over the expression of sadness and anger contributes to the frequently observed gender difference in the prevalence of depressive symptoms. As expected, women reported more depressive symptoms and were more ambivalent about the expression of anger than men. However, they were also more ambivalent to express sadness, which was partially in line with our hypotheses. Ambivalence to express sadness fully accounted for the gender differences in depressive symptoms. Ambivalence to express anger partially accounted for the gender differences in depressive symptoms, but not when controlling for the need to express sadness and anger. Furthermore, we found no evidence for moderation: the relation of sadness and anger ambivalence with depressive symptoms was similar in men and women. The gender differences in sadness and anger ambivalence also did not vary by depression status.

Our findings indicate that ambivalence to express sadness may contribute to depression susceptibility. As mentioned above, this might be due to the fact that an internal conflict itself puts strain on wellbeing (King and Emmons 1990) or that failure to express emotions clearly may impair social functioning (e.g., eliciting social support; Brockmeyer et al. 2013). The higher AEE scores in women may coincide with a tendency to ruminate (Nolen-Hoeksema 2012) and may reflect inhibition of adaptive emotional responses (Hyde et al. 2008). It is unlikely that these results reflect a stronger need to express sadness in women than men, as the need to express sadness and anger were unrelated to depressive symptoms (Appendix C).

Our findings suggest that targeting ambivalence to express sadness may be a promising strategy for psychotherapeutic or preventive interventions for depression, and this may be especially relevant in female patients. For instance, cognitive behavioral therapists may assess the functions and consequences of inhibiting emotions, and work towards more assertive and adaptive expressions of the patient's emotions (Beck 2011). In schema therapy, such interventions would be called addressing maladaptive schema's of emotional inhibition/deprivation, defectiveness or subjugation, and stimulating the 'healthy adult' mode (e.g., using imagery rescripting; Young et al. 2003). In acceptance and commitment therapy (ACT) and mindfulness approaches, patients may be stimulated to look at their sadness with a more accepting and mindful attitude, thereby decreasing the internal conflict (Hayes et al. 2004). Our findings suggest that discussing these themes may be more relevant for female than male depressed patients. Of course, due to the correlational nature of this study, reverse causation cannot be excluded and longitudinal and clinical studies are needed.

Interestingly, ambivalence over the expression of anger (AEE anger) partially accounted for the gender differences in depression, but not when controlling for the need to express sadness and anger. Consequently, the mediating role of AEE anger in the relation between gender and depression is less clear-cut than the role of AEE sadness. This was unexpected, as inhibited anger expression has been associated with impaired social functioning (Mongrain and Vettese 
Table 3 Effects of gender on AEE sadness and anger, by depression status

\begin{tabular}{|c|c|c|c|c|c|c|c|}
\hline & \multirow[t]{2}{*}{$B$} & \multirow[t]{2}{*}{$S E$} & \multirow[t]{2}{*}{$t$} & \multirow[t]{2}{*}{$p$} & \multicolumn{2}{|c|}{$95 \%$ BCA CI } & \multirow[t]{2}{*}{$R^{2}$} \\
\hline & & & & & Lower & Upper & \\
\hline \multicolumn{8}{|l|}{ AEE sadness } \\
\hline Male gender & -0.35 & 0.51 & -0.68 & .496 & -1.35 & 0.65 & .20 \\
\hline Depression status & 5.73 & 1.12 & 5.12 & $<.001$ & 3.53 & 7.93 & $F(9,540)=15.39, p<.001$ \\
\hline Male gender $*$ depression status & -1.48 & 0.81 & -1.84 & .066 & -3.07 & 0.10 & \\
\hline Age & -0.03 & 0.02 & -2.14 & .033 & -0.07 & -0.002 & $\Delta R^{2}$ due to interaction term \\
\hline Need to express sadness & -0.02 & 0.16 & -0.13 & .900 & -0.34 & 0.30 & .005 \\
\hline Need to express anger & 0.18 & 0.15 & 1.21 & .229 & -0.11 & 0.48 & $F(1,540)=3.39, p=.066$ \\
\hline \multicolumn{8}{|l|}{ Education $^{\mathrm{a}}$} \\
\hline Vocational training & -0.08 & 0.80 & -0.10 & .923 & -1.64 & 1.49 & \\
\hline Applied sciences & -1.21 & 0.65 & -1.87 & .062 & -2.49 & 0.062 & \\
\hline University college & -0.39 & 0.62 & -0.63 & .530 & -1.61 & 0.830 & \\
\hline \multicolumn{8}{|c|}{ Conditional effects of gender on AEE sadness by depression status } \\
\hline Not depressed & -0.35 & 0.51 & -0.68 & .496 & -1.35 & 0.65 & \\
\hline Depressed & -1.83 & 0.64 & -2.85 & .004 & -3.09 & -0.57 & \\
\hline \multicolumn{8}{|l|}{ AEE anger } \\
\hline Male gender & 0.24 & 0.47 & 0.51 & .609 & -0.68 & 1.16 & .16 \\
\hline Depression status & 3.58 & 1.03 & 3.46 & .001 & 1.55 & 5.61 & $F(9,540)=11.06, p<.001$ \\
\hline Male gender $*$ depression status & -0.99 & 0.74 & -1.33 & .185 & -2.45 & 0.47 & \\
\hline Age & 0.004 & 0.01 & 0.29 & .775 & -0.02 & 0.03 & $\Delta R^{2}$ due to interaction term \\
\hline Need to express sadness & 0.56 & 0.15 & 3.76 & $<.001$ & 0.27 & 0.86 & .003 \\
\hline Need to express anger & 0.63 & 0.14 & 4.57 & $<.001$ & 0.36 & 0.91 & $F(1,540)=1.76, p=.185$ \\
\hline \multicolumn{8}{|l|}{ Education $^{\mathrm{a}}$} \\
\hline Vocational training & -0.14 & 0.74 & -0.19 & .846 & -1.59 & 1.30 & \\
\hline Applied sciences & -0.76 & 0.60 & -1.27 & .205 & -1.93 & 0.42 & \\
\hline University college & -0.13 & 0.57 & -0.23 & .821 & -1.26 & 1.00 & \\
\hline \multicolumn{8}{|c|}{ Conditional effects of gender on AEE anger by depression status } \\
\hline Not depressed & 0.24 & 0.47 & 0.51 & 609 & -0.68 & 1.16 & \\
\hline Depressed & -0.75 & 0.59 & -1.26 & .208 & -1.91 & 0.42 & \\
\hline
\end{tabular}

${ }^{\mathrm{a}}$ Reference category: primary or secondary education only

2003). Perhaps the extent to which AEE anger contributes to depression vulnerability depends on other individual differences (e.g., sensitivity towards others; Karreman and Bekker 2012).

Women were not only more ambivalent than men to express anger, but also sadness. This is partly in contrast with previous research showing more negative social consequences of displaying sadness in men than women (e.g., Martin et al. 2013; Perry-Parisch and Zeman 2011). Women's higher AEE is in line with King and Emmons (1990). Women may experience emotions at higher intensity (Brebner 2003) and/or they may have a higher need to express emotions than men. However, the need to express sadness and anger were not (sadness) or weakly (anger) related to AEE (Appendix C). The inconsistency between the present results and previous studies on gender and emotional expression (Perry-Parisch and Zeman 2011; Williams and Tiedens 2016), suggest that mechanisms beyond gender-related social discouragement of emotional expression may play a role in the higher AEE among women than men (e.g., biological factors; gender-related life events; Hyde et al. 2008). The explanation of gender differences in AEE requires further (longitudinal) investigation. Our results regarding the relation between AEE and depressive symptoms are in line with previous studies (e.g., Brockmeyer et al. 2013). Of course, as this was a cross-sectional survey, reverse causation cannot be excluded.

Limitations of this study include the representativeness of the sample. In particular, the participants were relatively young and highly educated. The average severity of depressive symptoms was mild (Schulte-van Maaren et al. 2013; Rush et al. 2003; Wahl et al. 2014) and only very few reported more than a moderate severity. Respondents' mean AEE sadness and anger scores were in line with mean AEQ scores in a German nationally representative sample (Albani et al. 2007). Our use of a correlational design is a limitation, 
precluding conclusions about the directionality of the relationships. Also, the adapted AEE sadness and anger scales were constructed for the present study as a means to explore the present hypotheses. Although psychometric qualities of our AEE sadness and anger questionnaires seemed satisfactory, the assessment of AEE for separate emotions needs to be developed further. Furthermore, self-report measures have obvious drawbacks, including possible overestimation of depressive symptoms and measures were not validity checked or counterbalanced. Finally, several potential confounding variables (e.g., personality traits, gender role, social and emotional skills) were not assessed in this study.

Within these limits, our findings extend previous research by indicating that ambivalence over the expression of emotions, in particular sadness, may contribute to the higher prevalence of depressive symptoms in women than men. Although gender differences in AEE appear to be global rather than specific to anger and sadness, women's higher AEE for sadness in particular may be related to their higher depression vulnerability compared with men. Further research is warranted on the exact mechanisms underlying this relationship. These results imply that targeting AEE during depression treatment may help patients to better regulate emotions (Brockmeyer et al. 2013), and this may be especially relevant for female patients.

Acknowledgements We want to thank the following students for their assistance in data collection: Maron van Beuningen, Rosie Kidane, Rebecca Sein and Lieke van Wensveen.

Funding This study was funded by Leiden University.

Data Availability The dataset analysed during the current study is available in the Data Archiving and Networked Services (DANS) repository (https://doi.org/10.17026/dans-zdq-tb68).

\section{Compliance with Ethical Standards}

Conflict of Interest Laura Kunst, Judith de Groot and Willem van der Does declare that they have no conflict of interest.

Informed Consent The study was approved by the Psychology Research Ethics Committee (PREC\#9140377315). Informed consent was obtained from all individual participants included in the study.

Animal Rights No animal studies were carried out by the authors for this article.

Open Access This article is distributed under the terms of the Creative Commons Attribution 4.0 International License (http://creativeco mmons.org/licenses/by/4.0/), which permits unrestricted use, distribution, and reproduction in any medium, provided you give appropriate credit to the original author(s) and the source, provide a link to the Creative Commons license, and indicate if changes were made.

\section{References}

Albani, C., Blaser, G., Völker, J., Geyer, M., Schmutzer, G., Bailer, H., ... Traue, H. C. (2007). Ambivalence over emotional expressiveness: Psychometric evaluation of the AEQ-G18 in a representative German survey. GMS Psycho-Social Medicine, 4, Doc10.

Barber, J. A., \& Thompson, S. G. (2000). Analysis of cost data in randomized trials: An application of the non-parametric bootstrap. Statistics in Medicine, 19, 3219-3236.

Baron, R. M., \& Kenny, D. A. (1986). The moderator-mediator variable distinction in social psychological research: Conceptual, strategic, and statistical considerations. Journal of Personality and Social Psychology, 51(6), 1173. https://doi. org/10.1037/0022-3514.51.6.1173.

Beck, J. (2011). Cognitive behavior therapy: Basics and beyond (2nd ed.). New York: Guilford Press.

Ben-Zur, H., \& Zimmerman, M. (2005). Aging Holocaust survivors' well-being and adjustment: Associations with ambivalence over emotional expression. Psychology and Aging, 20(4), 710-713. https://doi.org/10.1037/0882-7974.20.4.710.

Brebner, J. (2003). Gender and emotions. Personality and Individual Differences, 34(3), 387-394. https://doi.org/10.1016/S0191 $-8869(02) 00059-4$.

Brockmeyer, T., Holtforth, M. G., Krieger, T., Altenstein, D., Doerig, N., Friederich, H. C., \& Bents, H. (2013). Ambivalence over emotional expression in major depression. Personality and Individual Differences, 54(7), 862-864. https://doi. org/10.1111/j.1559-1816.1999.tb01386.x.

Fritz, M. S., \& MacKinnon, D. P. (2007). Required sample size to detect the mediated effect. Psychological Science, 18(3), 233-239. https://doi.org/10.1111/j.1467-9280.2007.01882.x.

Gariépy, G., Honkaniemi, H., \& Quesnel-Vallée, A. (2016). Social support and protection from depression: Systematic review of current findings in Western countries. British Journal of Psychiatry, 209(4), 284-293. https://doi.org/10.1192/bjp.bp.115.169094.

Hayes, S., Follette, V., \& Linehan, M. (2004). Mindfulness and acceptance: Expanding the cognitive-behavioral tradition. New York: Guilford Press.

Hendriks, M. C. P., Croon, M. A., \& Vingerhoets, A. (2008). Social reactions to adult crying: The help-soliciting function of tears. Journal of Social Psychology, 148(1), 22-41. https://doi. org/10.3200/socp.148.1.22-42.

Hyde, J. S., Mezulis, A. H., \& Abramson, L. Y. (2008). The ABCs of depression: Integrating affective, biological, and cognitive models to explain the emergence of the gender difference in depression. Psychological Review, 115(2), 291. https://doi. org/10.1037/0033-295X.115.2.291.

Karreman, A., \& Bekker, M. H. J. (2012). Feeling angry and acting angry: Different effects of autonomy-connectedness in boys and girls. Journal of Adolescence, 35, 407-415.

King, L. A., \& Emmons, R. A. (1990). Conflict over emotional expression: Psychological and physical correlates. Journal of Personality and Social Psychology, 58(5), 864. https://doi. org/10.1037//0022-3514.58.5.864.

Klok, M. D., Giltay, E. J., Van der Does, A. J. W., Geleijnse, J. M., Antypa, N., Penninx, B. W. J. H., ... Zitman, F. G. (2011). A common and functional mineralocorticoid receptor haplotype enhances optimism and protects against depression in females. Translational Psychiatry, 1(12), e62.

Krause, E. D., Mendelson, T., \& Lynch, T. R. (2003). Childhood emotional invalidation and adult psychological distress: The mediating role of emotional inhibition. Child Abuse \& Neglect, 27(2), 199-213. https://doi.org/10.1016/s0145-2134(02)00536-7.

Martin, L. A., Neighbors, H. W., \& Griffith, D. M. (2013). The experience of symptoms of depression in men vs women: Analysis 
of the National Comorbidity Survey Replication. JAMA Psychiatry, 70(10), 1100-1106. https://doi.org/10.1001/jamapsychi atry.2013.1985.

Mongrain, M., \& Vettese, L. C. (2003). Conflict over emotional expression: Implications for interpersonal communication. Personality and Social Psychology Bulletin, 29(4), 545-555. https://doi. org/10.1177/014616720250924.

Mongrain, M., \& Zuroff, D. C. (1994). Ambivalence over emotional expression and negative life events: Mediators of depressive symptoms in dependent and self-critical individuals. Personality and Individual Differences, 16(3), 447-458. https://doi. org/10.1016/0191-8869(94)90071-x.

Müller, J., Bühner, M., Ziegler, M., \& Şahin, L. (2008). Are alexithymia, ambivalence over emotional expression, and social insecurity overlapping constructs? Journal of Psychosomatic Research, 64, 319-325. https://doi.org/10.1016/j.jpsychores.2007.10.005.

Neal, D. J., \& Simon, J. S. (2007). Inference in regression models of heavily skewed alcohol use data: A comparison of ordinary least squares, generalized linear models, and Bootstrap Resampling. Psychology of Addictive Behaviors, 21(4), 441-452. https://doi. org/10.1037/0893-164X.21.4.441.

Nolen-Hoeksema, S. (2012). Emotion regulation and psychopathology: The role of gender. Annual Review of Clinical Psychology, 8, 161187. https://doi.org/10.1146/annurev-clinpsy-032511-143109.

Parra-Frutos, I. (2014). Controlling the Type I error rate by using the nonparametric bootstrap when comparing means. British Journal of Mathematical and Statistical Psychology, 67, 117-132. https:// doi.org/10.1111/bmsp.12011.

Perry-Parrish, C., \& Zeman, J. (2011). Relations among sadness regulation, peer acceptance, and social functioning in early adolescence: The role of gender. Social Development, 20(1), 135-153. https://doi.org/10.1111/j.1467-9507.2009.00568.x

Preacher, K. J., \& Hayes, A. F. (2008). Asymptotic and resampling strategies for assessing and comparing indirect effects in multiple mediator models. Behavior Research Methods, 40(3), 879-891. https://doi.org/10.3758/BRM.40.3.879.

Quinton, S., \& Wagner, H. L. (2005). Alexithymia, ambivalence over emotional expression, and eating attitudes. Personality and Individual Differences, 38(5), 1163-1173. https://doi. org/10.1016/j.paid.2004.07.013.

Rueger, S. Y., Malecki, C. K., Pyun, Y., Aycock, C., \& Coyle, S. (2016). A meta-analytic review of the association between perceived social support and depression in childhood and adolescence. Psychological Bulletin, 142(10), 1017-1067. https://doi. org/10.1037/bul0000058.

Rush, A. J., Trivedi, M. H., Ibrahim, H. M., Carmody, T. J., Arnow, B., Klein, D. N., ... Keller, M. B. (2003). The 16-Item Quick Inventory of Depressive Symptomatology (QIDS), clinician rating (QIDS-C), and self-report (QIDS-SR): A psychometric evaluation in patients with chronic major depression. Biological Psychiatry, 54(5), 573-583. https://doi.org/10.1016/S0006-3223(02)01866-8.

Salk, R. H., Hyde, J. S., \& Abramson, L. Y. (2017). Gender differences in depression in representative national samples: Meta-analyses of diagnoses and symptoms. Psychological Bulletin, 143(8), 783822. https://doi.org/10.1037/bul0000102.

Santagio-Menendez, M., \& Campbell, A. (2013). Sadness and anger: Boys, girls, and crying in adolescence. Psychology of Men \& Masculinity, 14(4), 400. https://doi.org/10.1037/a0030661.

Schulte-van Maaren, Y. W. M., Carlier, I. V. E., Zitman, F. G., van Hemert, A. M., de Waal, M. W. M., van der Does, A. J. W., ... Giltay, E. J. (2013). Reference values for major depression questionnaires: The Leiden Routine Outcome Monitoring Study. Journal of Affective Disorders, 149(1-3), 342-349. https://doi. org/10.1016/j.jad.2013.02.009.

Wahl, I., Lowe, B., Bjorner, J. B., Fischer, F., Langs, G., Voderholzer, U., ... Rose, M. (2014). Standardization of depression measurement: A common metric was developed for 11 self-report depression measures. Journal of Clinical Epidemiology, 67(1), 73-86. https://doi.org/10.1016/j.jclinepi.2013.04.019.

Williams, M. J., \& Tiedens, L. Z. (2016). The subtle suspension of backlash: A meta-analysis of penalties for women's implicit and explicit dominance behavior. Psychological Bulletin, 142(2), 165-197. https://doi.org/10.1037/bul0000039.

Young, J. E., Klosko, J. S., \& Weishaar, M. (2003). Schema Therapy: A Practitioner's Guide. New York: Guilford. 